\title{
ANÁLISIS DE LAS PRINCIPALES DIFERENCIAS EN LA IMPLEMENTACIÓN DE ESTRATEGIAS ALTERNATIVAS ENTRE HEDGE FUNDS Y UCITS
}

\author{
Autor: Juan Infante Infante ${ }^{1}$ \\ Responsable Distribución Fondos de UBS Global Asset Management \\ para España y Portugal
}

\section{Resumen}

En los últimos años, la legislación aplicable a la industria de fondos UCITS ha evolucionado para poder acercar estos vehículos de inversión a los hedge funds. Sin embargo, aún siguen presentando dificultades a la hora de implementar determinadas estrategias como consecuencia de las restricciones y limitaciones impuestas por dicha legislación. Por ello, este estudio analiza los principales problemas que tienen los fondos UCITS a la hora de implementar estrategias similares a las implementadas por los hedge funds, así como las ventajas y desventajas que presentan con respecto a estos últimos derivadas de la fuerte regulación a la que están sujetos.

\footnotetext{
${ }^{1}$ juan.infante@ubs.com
} 
Palabras clave: Fondos UCITS; fondos de cobertura (hedge funds); estrategias, diferencias; restricciones; límites; legislación; ventajas; desventajas.

Analysis of the main differences in the implementation of alternative strategies between hedge funds and UCITS

\begin{abstract}
In recent years, the UCITS industry's applicable legislation has evolved to make UCITS more similar to hedge funds. However, and regardless the fact that UCITS currently have a great number of investment possibilities, they still have difficulties when implementing certain strategies as a result of the restrictions and limitations imposed by applicable law, which is primarily aimed at protecting investors. Therefore, this study analyzes the main problems of UCITS when implementing strategies similar to those implemented by hedge funds, as well as the advantages and disadvantages of UCITS funds derived from the limitations and restrictions faced by these investment vehicles.
\end{abstract}

Key words: UCITS funds; hedge funds; strategies; differences; restrictions; limits; legislation; advantages; disadvantages.

\title{
1. INTRODUCCIÓN
}

Dentro de la industria de gestión de activos a nivel global destacan sobre otras alternativas de inversión, principalmente por el atractivo que presentan a inversores de todas partes del mundo, por un lado, los fondos de cobertura o hedge funds y, por el otro, los fondos UCITS. Ambos vehículos de inversión son, en la actualidad, las principales alternativas para todos aquellos inversores que buscan unas rentabilidades elevadas manteniendo los riesgos asumidos de un modo contenido.

En este sentido, los fondos de cobertura son capaces de implementar cualquier tipo de estrategia alternativa sin mayores dificultades, gracias a la prácticamente nula legislación encargada de regular a su industria mientras que, por su parte, los UCITS se enfrentan a una serie de restricciones impuestas por la legislación aplicable a este tipo de fondos, las cuales están destinadas a proteger los intereses de los inversores, que les limita en gran medida a la hora de desarrollar determinadas estrategias. 
Esta eficiente legislación, la cual otorga una importante flexibilidad a los gestores, a la par que una protección importante a los inversores, explica en gran medida el hecho de que la industria de fondos UCITS haya venido experimentando un gran crecimiento en los últimos años. Junto a ello, los UCITS también han visto cómo su cada vez mayor flexibilidad les permite, en la actualidad, llevar a cabo un gran número de estrategias alternativas de retorno absoluto muy similares a las implementadas por los fondos de cobertura. Sin embargo, la puesta en práctica de estas estrategias por parte de los fondos UCITS presenta una serie de dificultades derivadas, en gran parte, de las limitaciones, restricciones y obligaciones que la eficiente y robusta legislación actual encargada de regular a la industria exige a este tipo de vehículos de inversión.

Todos estos aspectos anteriormente mencionados, hacen que los UCITS presenten una serie de ventajas y desventajas con respecto a otras alternativas, como por ejemplo los hedge funds, que se derivan en gran medida de las obligaciones recogidas en la legislación encargada de regular a la industria, y que han de ser consideradas por todos aquellos inversores que se estén planteando llevar a cabo inversiones en este tipo de vehículos de inversión.

Por ello, este estudio tiene como principal objetivo el analizar las diferencias existentes entre fondos UCITS y fondos de cobertura a la hora de implementar estrategias alternativas, las cuales a su vez emanan de las muy importantes divergencias que existen en términos de regulación aplicable a ambos vehículos de inversión. En primer lugar, se definirán los fondos UCITS y se observarán los principales límites, restricciones y obligaciones recogidas por la legislación actual encargada de regular a la industria. Posteriormente, se enumerarán las principales estrategias alternativas puestas en funcionamiento por los fondos de cobertura y por los UCITS, así como los principales problemas a los que se enfrentan estos últimos habitualmente a la hora de poner en práctica todas ellas. Tras ello, se examinarán las ventajas y desventajas de los fondos UCITS frente a otras alternativas de inversión. Finalmente, se presentarán las conclusiones a las cuales ha llevado el estudio.

\section{FONDOS UCITS: PRINCIPALES RESTRICCIONES EN LA IMPLEMENTACIÓN DE ESTRATEGIAS ALTERNATIVAS}

Los fondos UCITS² (Undertakings for Collective Investment in Transferable Securities) son vehículos de inversión colectiva establecidos en la Unión Europea y

\footnotetext{
${ }^{2}$ Stefanini, F.; Vismara, S.; Meoli, M.; Derossi, T., Newcits: Investing in UCITS Compliant Hedge Funds. Wiley, UK, 2010. Szylar, C., UCITS Handbook. Wiley, UK, 2012.
} 
autorizados bajo un marco legal armonizado, que permite que todo aquel fondo UCITS que haya sido registrado en un país de la Unión Europea pueda ser comercializado, ya no sólo en el país en el cual ha sido registrado y autorizado, sino también en cualquier otro país de la Unión, sin necesidad de requerimientos adicionales por parte de cualquiera de las autoridades encargadas de la supervisión de los mercados financieros existentes en cada uno de los países en los que se decida comercializar el fondo.

\subsection{Restricciones y limitaciones aplicables a los fondos UCITS}

El marco legal armonizado encargado de regular las actividades de los fondos UCITS tiene como principal objetivo el facilitar a este tipo de vehículos de inversión la implementación de estrategias que les permitan obtener rendimientos atractivos, así como la protección de los intereses de los inversores, para lo cual introduce una serie de restricciones de obligado cumplimiento por este tipo de fondos de inversión que les restan flexibilidad en comparación con los fondos de cobertura. En este sentido, la Directiva 85/611/EEC del año $1985^{3}$ introdujo los siguientes límites a considerar por los UCITS a la hora de llevar a cabo sus inversiones:

- Un fondo UCITS no podrá llevar a cabo inversiones por un valor superior al 10\% de sus activos bajo gestión en instrumentos que no estén admitidos a negociación en alguna de las principales bolsas de valores del mundo. Por lo general, el único requisito que han de cumplir este tipo de activos será el presentar un nivel elevado de liquidez.

- Para asegurar una correcta diversificación y una protección a los inversores del riesgo de concentración, un fondo UCITS no podrá llevar a cabo, por norma general, inversiones por un valor superior al 5\% de sus activos bajo gestión en activos de un mismo emisor aunque, en determinados supuestos especiales, los estados miembros podrán aumentar este límite.

- Cualquiera de los estados miembros de la Unión Europea podrá permitir a un fondo UCITS el llevar a cabo inversiones de, como máximo, el 10\% de sus activos bajo gestión, en instrumentos de renta fija que presenten un carácter similar a los instrumentos de renta variable admitidos a negociación en una bolsa de valores. En este sentido, los instrumentos de renta fija deberán presentar un carácter muy líquido y un precio que sea relativamente sencillo de calcular en cualquier momento.

\footnotetext{
${ }^{3}$ Puede accederse a una versión digital de esta directiva, la cual se conoce también como UCITS I, a través del sitio web de la ESMA en el siguiente enlace: http://www.esma.europa.eu/system/files/ Dir_85_611. PDF (05/06/2015).
} 
- Los fondos UCITS tendrán la posibilidad de invertir la totalidad de sus activos bajo gestión en distintos activos que estén garantizados por alguno de los estados miembros o por sus autoridades locales, así como por cualquier otro estado no perteneciente a la Unión Europea u organismos internacionales en los que participe y sea miembro alguno de los países de la Unión Europea. En este sentido, un fondo UCITS tendrá la obligación de invertir en al menos 6 emisiones distintas, siempre y cuando no invierta más de un 30\% de sus activos bajo gestión en una sola de dichas emisiones.

- Por su parte, una compañía gestora encargada de gestionar un fondo UCITS tendrá que hacer frente a determinadas obligaciones que le impiden comprar acciones que lleven aparejadas un suficiente número de derechos de votos como para que dicha compañía gestora sea capaz de influenciar en las decisiones del equipo gestor del emisor de dichos títulos.

- Un fondo UCITS podrá adquirir cualquier tipo de activo fijo, incluyendo bienes inmuebles, siempre y cuando sean necesarios para llevar a cabo sus actividades cotidianas.

- Por su parte, con carácter general, un fondo UCITS o una compañía gestora no podrá pedir prestado aunque, en ciertas ocasiones, un estado miembro podrá otorgar autorización para solicitar préstamos de forma temporal, en especial en casos en los que se requieran fondos adicionales para comprar bienes inmuebles necesarios para llevar a cabo las actividades ordinarias del fondo, pero siempre y cuando dichos préstamos no presenten un valor superior al 10\% de los activos bajo gestión.

- En ningún momento, un fondo UCITS podrá llevar a cabo ventas en corto al descubierto ni inversiones en metales preciosos o certificados representativos de dichas materias primas.

- Un UCITS no podrá llevar a cabo inversiones por un valor superior al 5\% de sus activos bajo gestión en otros fondos que no se encuentren bajo el marco regulatorio armonizado de la Directiva.

- Los distintos estados miembros de la Unión Europea a su vez serán los encargados de autorizar a los fondos UCITS el uso de distintas técnicas de gestión de activos destinadas a aumentar la eficiencia en la gestión y garantizar la correcta puesta en marcha de actuaciones que permitan alcanzar los objetivos definidos por el propio fondo.

Tal y como se puede suponer, el gran número de restricciones y obligaciones que imponía la Directiva anterior a los fondos UCITS a la hora de llevar a cabo sus inversiones, impactaba en gran medida en la flexibilidad de la que disponían este tipo de vehículos de inversión para competir con los enormemente flexibles fondos de cobertura. Debido a este motivo, se antojaba como 
imprescindible la introducción de nuevas medidas destinadas a otorgar una mayor flexibilidad a los fondos UCITS, pero sin dejar de lado la importante protección a los inversores que otorgaba el marco legal encargado de regular a la industria.

Esta reforma, se materializó en la Directiva 2001/108/EC 4 del año 2002, también conocida como Directiva de Producto, la cual introdujo importantes cambios destinados a permitir a los fondos UCITS el llevar a cabo inversiones en un mayor número de activos. El primer aspecto importante que incluye la Directiva es el hecho de que se define de manera más precisa el término valores mobiliarios en los cuales se permite llevar a cabo inversiones a los fondos UCITS. Dentro de esta definición ampliada, los valores mobiliarios en los que podrán invertir los fondos UCITS serán acciones de compañías u otros títulos equivalentes a dichas acciones, así como bonos y otros instrumentos de deuda emitidos por las compañías. Además, también se permitirá a los fondos UCITS el llevar a cabo inversiones en instrumentos del mercado monetario, los cuales tienen un carácter muy líquido y cuyo valor puede ser determinado en cualquier momento.

Junto a los aspectos anteriores, la Directiva también añadió nuevos activos en los cuales los fondos UCITS podrían llevar a cabo inversiones, dentro de los cuales destacan los siguientes:

- Depósitos en instituciones de crédito que puedan recuperarse en cualquier momento o que tengan una duración de un año como máximo, siempre y cuando dichas instituciones de crédito tengan una oficina registrada en alguno de los estados miembros. Además, también se permitirán las inversiones en depósitos en instituciones de crédito que no estén registradas en la Unión Europea, pero siempre y cuando dichas instituciones estén supervisadas de una manera similar a las de los estados miembros.

- Instrumentos del mercado monetario que no se intercambien en mercados regulados, siempre y cuando la emisión o el emisor de dichos instrumentos haya sido regulado para garantizar los intereses de los inversores. Algunos ejemplos son todos aquellos instrumentos emitidos o garantizados por un banco central o por una autoridad central, regional o local de alguno de los países de la Unión Europea; instrumentos emitidos o garantizados por el Banco Central Europeo, la Unión Europea o el Banco Europeo de Inversiones; así como todos aquellos instrumentos que hayan sido emitidos por países no pertenecientes a la Unión, pero siempre y cuando estén garantizados, entre otros.

${ }^{4}$ Una versión digital de esta Directiva, la cual es parte de lo que se conoce como UCITS III, está disponible en el sitio web de la ESMA a través del vínculo siguiente: http://www.esma.europa.eu/system/ files/Dir_01_108. PDF (05/06/2015). 
- Participaciones de otros fondos UCITS registrados en alguno de los estados miembros de la Unión Europea o en países terceros, siempre y cuando se cumplan ciertas condiciones que, por lo general, garanticen la protección de los intereses de los inversores.

- Instrumentos derivados de carácter financiero, ya sean intercambiados en mercados regulados o incluso OTC ${ }^{5}$ (over the counter). En este sentido, deberán cumplirse determinadas condiciones tales como que el subyacente sea un activo en el cual un fondo UCITS pueda llevar a cabo inversiones, ya sea un índice, tipos de interés o divisas; que la contrapartida en una operación que se lleve a cabo OTC esté supervisada por una autoridad competente; así como que pueda calcularse el valor de los instrumentos OTC diariamente, de modo que se pueda liquidar la transacción en cualquier momento.

- La Directiva también establece que la exposición total de un fondo UCITS a productos derivados no puede ser superior al valor neto de su cartera. Junto a ello, las inversiones llevadas a cabo en productos derivados estarán sujetas a ciertas restricciones que han de ser cumplidas en todo momento y que tienen como principal objetivo evitar que los inversores del fondo tengan que hacer frente a pérdidas importantes en aquellos casos en los que las apuestas realizadas en productos derivados hayan sido inadecuadas.

Por otro lado, dentro de los diversos límites establecidos a la hora de invertir que han de seguir los fondos UCITS destacan los siguientes:

- Un fondo UCITS no podrá invertir, por norma general, más del 5\% de sus activos gestionados en activos mobiliarios o activos de mercados monetarios emitidos por un mismo emisor, de igual modo que no podrá mantener más del 20\% de sus activos totales en depósitos en una misma entidad. No obstante, los estados miembros podrán aumentar el límite anteriormente mencionado en determinados supuestos especiales.

- En aquellos casos en los que un fondo UCITS entre en un repo ${ }^{6}$ (repurchase agreement) o en un reverse repo, deberá asegurarse de que podrá recuperar tanto el dinero, como los activos, incluidos dentro del acuerdo en cualquier momento.

- Un determinado fondo UCITS podrá invertir en otros fondos UCITS, siempre y cuando no invierta más del 10\% de sus activos bajo gestión en

${ }^{5}$ El término OTC hace referencia a un mercado no organizado en el que la negociación de instrumentos financieros se realiza bilateralmente entre las partes involucradas en la transacción.

${ }^{6}$ Un repo o acuerdo de recompra hace referencia a un contrato bilateral en el que una parte vende un determinado activo y a su vez se compromete a recomprarlo en una fecha futura a un determinado precio. 
un único fondo UCITS, aunque los estados miembros podrán aumentar el límite siempre que se cumplan ciertas condiciones.

- En productos derivados OTC, un fondo UCITS no podrá entrar en ninguna transacción que le obligue a tener una exposición de riesgo superior al 5\% de sus activos totales por norma general, o del 10\% en aquellos casos en los que la otra contrapartida sea una institución de crédito.

- Un fondo UCITS no podrá tener posiciones combinadas en activos mobiliarios, activos del mercado monetario, depósitos mantenidos o incluso transacciones de derivados OCT de un mismo emisor que, sumadas todas ellas, tengan un valor superior al $20 \%$ de sus activos gestionados.

- En ningún momento un fondo UCITS podrá invertir en activos inmobiliarios con el objetivo de especular; metales preciosos; préstamos bancarios; así como cualquier materia prima aunque, en este último caso, sí que se permite la contratación de productos derivados que tengan como subyacente a un determinado índice de materias primas.

- Por su parte, las ventas en corto al descubierto estarán prohibidas en todo momento tanto para las compañías de inversión, como para las compañías gestoras, para evitar posibles problemas que puedan aparecer y que puedan provocar situaciones en las que los inversores tengan que hacer frente a cuantiosas pérdidas. No obstante, hay que destacar que, independientemente de que los fondos UCITS no puedan vender en corto un determinado activo, ya sean acciones o bonos, de igual modo que lo hacen los hedge funds, sí que pueden construir una posición que tenga el mismo efecto por medio de la contratación de determinados productos derivados, pero sólo si el fondo UCITS presenta un carácter sofisticado.

\subsection{Principales diferencias entre fondos UCITS sofisticados y no sofisticados}

Otro aspecto a tener en cuenta es el hecho de que, a su vez, los fondos UCITS deben ser separados entre aquellos que presenten un carácter sofisticado, los cuales son gestionados utilizando técnicas más complejas y a los que se les permite invertir en ciertos productos derivados con objetivos distintos a los de cubrir posibles exposiciones, de aquellos otros que sean considerados como no sofisticados, los cuales están dirigidos a inversores con un perfil de riesgo mucho más conservador que los primeros. Tanto unos, como otros, presentan una serie de características que han de ser conocidas, las cuales se observarán a continuación.

Los fondos UCITS sofisticados son aquellos que, por las características que presentan, más similitudes tienen con los hedge funds. A este tipo de fondos, la legislación existente les permite implementar estrategias y procedimientos de inversión y de gestión más complejas que a los fondos no sofisticados, así como el 
invertir en activos con unos niveles de riesgo más elevados. Dentro de sus características, destacan las siguientes:

- Un fondo UCITS sofisticado deberá recoger en su correspondiente folleto los distintos productos derivados empleados en la estrategia de inversión, distinguiendo entre aquellos usados exclusivamente con el objetivo de cubrir exposiciones, de los empleados para maximizar los retornos de una determinada estrategia.

- Junto con la información anterior, los fondos sofisticados deberán detallar y enviar a las correspondientes autoridades competentes del país donde hayan sido registrados un informe en el que se detalle la metodología de gestión que se aplicará en el fondo, así como los distintos procedimientos de control interno y de gestión de riesgos que se utilizarán.

- Un fondo sofisticado, independientemente de que no tenga permitidas llevar a cabo ventas en corto, podrá entrar en transacciones de productos derivados que le permitan replicar el efecto de dichas ventas en corto aunque, en este caso, deberán detallarse y reportarse tanto a las autoridades competentes, como a los inversores del fondo.

- En todo momento, el fondo deberá informar tanto a sus inversores, como a las autoridades correspondientes, del nivel de riesgo asumido, para lo cual deberá calcular tanto la volatilidad, ya sea a nivel agregado o individualmente para cada una de las posiciones de la cartera, así como el $\mathrm{VaR}^{7}$ (value at risk) u otras métricas avanzadas destinadas a conocer los riesgos que presente una determinada cartera.

- A la hora de invertir en determinados activos, los fondos sofisticados podrán llevar a cabo inversiones de una manera mucho más flexible, lo cual les acerca en gran medida a los hedge funds aunque, no obstante, seguirán teniendo restricciones de inversión a la hora de invertir en algunos activos, como por ejemplo bienes inmobiliarios o materias primas, así como ciertos límites aplicables a las inversiones llevadas a cabo.

- Todas las características anteriormente mencionadas, hacen que este tipo de fondos esté destinado a inversores que presenten un perfil de riesgo moderado o alto ya que, independientemente de que estén sujetos a una regulación estricta y a determinados límites a la hora de implementar determinadas estrategias, las posibilidades que estos fondos tienen de obtener unos mayores

${ }^{7} \mathrm{El} \mathrm{VaR}$ es una de las medidas estadísticas más utilizadas para determinar el riesgo de una determinada cartera o empresa. Se define como la pérdida máxima que se espera tenga la cartera (o la empresa) en un periodo de tiempo determinado y para un determinado intervalo de confianza. Por ejemplo, si una cartera tiene un VaR a 1 día de 10 millones de USD, con un intervalo de confianza del 95\%, indicará que en 1 de cada 20 días (o 5\% de los días), la pérdida esperada será superior a 10 millones de USD. En otras palabras, hay una probabilidad del 5\% de que la cartera tenga unas pérdidas en un día superiores a 10 millones de USD. 
retornos debido a su mayor flexibilidad, vienen aparejadas de unos mayores riesgos que han de ser asumidos por los inversores.

Por otro lado, los fondos UCITS no sofisticados, presentan una flexibilidad limitada a la hora de operar, ya que tienen como principal objetivo la preservación del capital de sus inversores. Dentro de sus características principales, destacan las siguientes:

- Los fondos UCITS no sofisticados podrán llevar a cabo inversiones, al igual que los sofisticados, en activos mobiliarios, activos del mercado monetario e instrumentos de deuda y depósitos, siempre y cuando respeten los límites recogidos en la legislación existente.

- En el caso de los fondos no sofisticados, no tendrán obligación alguna de reportar dentro de los objetivos de inversión los productos derivados utilizados, ya que se entenderá que dichos productos serán usados exclusivamente para aumentar la eficiencia en la gestión del fondo y no para implementar estrategias destinadas a aumentar los retornos.

- Por su parte y, al contrario que los fondos sofisticados, los fondos UCITS no sofisticados no podrán usar productos derivados a no ser que dichos productos sean usados exclusivamente para cubrir exposiciones de la cartera. En otras palabras, los productos derivados deberán usarse como parte de una gestión de la cartera eficiente que tenga como principal objetivo el preservar el capital de los inversores y garantizar los intereses de los mismos, así como el alcanzar los objetivos del fondo.

- Derivado del aspecto exterior, un fondo no sofisticado no podrá entrar en transacciones de productos derivados con el objetivo de replicar el efecto de las ventas en corto, por lo que el fondo se comportará como un fondo de inversión que presente exclusivamente posiciones largas.

- Todo aquel fondo UCITS que presente un carácter no sofisticado, tendrá que implementar procedimientos destinados a la gestión del riesgo que sean lo suficientemente robustos como para garantizar y proteger los intereses de los inversores, aunque no tendrá la obligación de calcular métricas complejas, como por ejemplo el VaR. En este sentido, bastará con que el fondo tenga en cuenta, a la hora de calcular el riesgo, aspectos tales como las exposiciones con determinadas contrapartes, los riesgos de contrapartida, así como los posibles movimientos futuros del mercado.

- Todos los aspectos anteriores, hacen que los fondos UCITS no sofisticados estén destinados exclusivamente a inversores con un perfil de riesgo bajo, ya que la poca flexibilidad que la legislación permite a este tipo de fondos tiene como principal objetivo el que todos ellos se centren en la preservación del capital de los inversores y en que los riesgos asumidos por el fondo sean mínimos. 


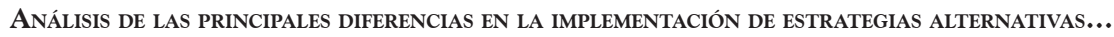

\title{
3. PRINCIPALES DIFERENCIAS EN LA IMPLEMENTACIÓN DE ESTRATEGIAS ALTERNATIVAS ENTRE UCITS Y HEDGE FUNDS
}

\author{
Tabla 1. Nivel de dificultad en la implementación de estrategias \\ por parte de fondos UCITS
}

\begin{tabular}{|c|c|}
\hline Fácil & Long-only. \\
\hline Media & $\begin{array}{c}\text { Long/short, equity market neutral, event driven, arbitraje en renta fija, arbi- } \\
\text { traje con bonos convertibles, global macro, futuros gestionados y fondos de } \\
\text { fondos. }\end{array}$ \\
\hline Difícil & Dedicated short, valores en dificultades y mercados emergentes. \\
\hline
\end{tabular}

Fuente: elaboración propia.

La tabla anterior muestra las principales estrategias implementadas por los UCITS, las cuales se han dividido en función del nivel de dificultad que presentan a la hora de implementarse. El nivel de dificultad varía en gran medida en función del tipo de estrategia que se pretenda implementar ${ }^{8}$, y se deriva de las restricciones y limitaciones a las que están sujetos estos vehículos de inversión. No obstante y, antes de pasar a observar las diferentes estrategias implementadas por los fondos de cobertura y por los fondos UCITS, así como las principales dificultades a las que se enfrentan estos últimos a la hora de ponerlas en marcha, es preciso definir lo que se entiende por fondo de cobertura.

Los fondos de cobertura o hedge funds se definen como todos aquellos vehículos de inversión flexibles, laxamente regulados y destinados a inversores sofisticados, que tratan de obtener rendimientos absolutos por medio de la implementación de una serie de estrategias que se caracterizan por presentar un carácter no convencional en comparación con las puestas en funcionamiento habitualmente en la industria de fondos de inversión tradicional. Una vez definido un fondo de cobertura, es momento de enumerar las principales estrategias puestas en funcionamiento por los hedge funds y por los UCITS, así como las diferencias a la hora de implementarlas entre unos y otros ${ }^{9}$, ya que, tal y como se ha hecho referencia con anterioridad, los fondos UCITS están sujetos a una estricta regulación que

\footnotetext{
${ }^{8}$ El nivel de dificultad fácil hace referencia a que las restricciones a las que están sujetos los fondos no impiden en gran medida la implementación de la estrategia. Por otro lado, una dificultad media indica que las restricciones impuestas a los fondos hacen que la puesta en práctica de la estrategia sea complicada. Por último, un nivel de dificultad difícil se refiere a que las restricciones limitan en gran medida la implementación de la estrategia.

${ }^{9}$ Lhabitant, F., Handbook of Hedge Funds. Wiley, USA, 2006. Stefanini, F., Investment Strategies of Hedge Funds. Wiley, UK, 2006.
} 
les impone una serie de límites y restricciones que han de considerar a la hora de llevar a cabo sus estrategias y que tienen como principal objetivo el proteger los intereses de los inversores. No obstante, ello no impide el que este tipo de vehículos de inversión ponga en marcha estrategias alternativas similares a las implementadas por los fondos de cobertura aunque, para ello, han de ser adaptadas a los requerimientos exigidos por la legislación encargada de regular sus actividades. Dentro de estas estrategias, destacan las siguientes:

- Estrategias Largas (Long-only strategies): en estas estrategias, el gestor tomará posiciones largas, las cuales se basarán en un profundo análisis llevado a cabo, en aquellos activos que estén infravalorados. Algunos de los diversos activos en los que pueden invertir los fondos son instrumentos de renta variable, renta fija, mercados monetarios, determinados productos derivados y, en definitiva, todos aquellos instrumentos que, de acuerdo con la legislación existente, tengan un carácter elegible y cumplan los requisitos de liquidez exigidos por la misma. Por su parte, en estas estrategias y, al contrario de lo que sucede en las de tipo long/short, el gestor mantiene exclusivamente posiciones largas, lo que facilita en gran medida la implementación de las mismas. Además, en aquellas situaciones en las que el mercado se encuentre en una tendencia alcista, la posición podrá permitir obtener unos rendimientos mayores, ya que no habrá posiciones cortas que compensen parte de los rendimientos obtenidos. En el lado negativo, decir que estas estrategias pueden provocar pérdidas en aquellas situaciones en las que el mercado esté en una tendencia bajista, ya que el gestor no dispondrá de posiciones cortas que le permitan obtener rendimientos positivos en situaciones de mercado bajistas o que le sirvan para cubrir parte de los riesgos asumidos con las posiciones largas.

- Estrategias Largas/Cortas (Long/short strategies) ${ }^{10}$ : el objetivo de esta estrategia consiste en crear una posición combinada de posiciones largas y cortas en determinados activos que permita minimizar los riesgos asumidos y, a su vez, obtener retornos superiores a los del mercado. En otras palabras, el gestor tomará posiciones largas en aquellos activos que crea que están infravalorados o que presenten un potencial de crecimiento elevado, y venderá en corto activos que crea que están sobrevalorados o que tengan problemas que pongan en riesgo su precio en un futuro.

En este sentido y, dadas las distintas limitaciones que tienen los fondos UCITS a la hora de llevar a cabo sus inversiones, estas estrategias han de ser adaptadas a dichos límites y restricciones para poder implementarse. Por

${ }^{10}$ Leibowitz, M., Emrich, S. and Bova, A., Modern Portfolio Management: Active Long/Short 130/30 Equity Strategies. Wiley, USA, 2009. 
ello, el gestor deberá invertir en todos aquellos activos que sean elegibles y que presenten un nivel mínimo de liquidez, todo ello considerando los límites aplicables a la hora de apalancarse. Además, para las posiciones cortas y, dado que los fondos UCITS no pueden vender en corto activos, el gestor deberá utilizar determinados productos derivados que le permitan obtener el mismo efecto que una venta en corto. Por lo general, los instrumentos derivados utilizados para replicar el comportamiento de las ventas en corto suelen ser los conocidos como contratos por diferencias (CFD o contract for difference) y los SWAPS, siendo estos últimos los más habituales.

Los contratos por diferencias son instrumentos acordados entre dos partes, un comprador y un vendedor, en los que el vendedor se compromete a pagar al comprador la diferencia entre el precio futuro y el precio de un determinado activo al momento de la contratación del CFD. En los casos en los que dicha diferencia sea negativa, será el comprador el que pague la diferencia al vendedor. En este sentido, a la hora de replicar el comportamiento de una determinada posición corta, los gestores de fondos UCITS serán la parte vendedora en los CFDs, de modo que obtendrán un beneficio siempre y cuando el precio futuro del activo subyacente de dichos contratos sea inferior al precio del activo en el momento de la contratación del CFD.

Por otro lado, los SWAPS o permutas financieras utilizados por los gestores de fondos UCITS para replicar el efecto de posiciones cortas, son instrumentos a través de los cuales un determinado bróker toma prestadas acciones, u otro instrumento, de un prestamista para venderlas en corto. Posteriormente, entrega los fondos obtenidos de la venta en corto al prestamista como colateral, quien los invierte a un determinado tipo de interés que, una vez descontado el coste del préstamo o borrow rate, paga al bróker. Después, el bróker pagará al fondo UCITS el tipo de interés recibido del prestamista menos un diferencial o spread fijo que será ligeramente inferior al borrow rate que ha pagado al prestamista. Además, junto a este concepto, el bróker también cobrará al fondo una determinada comisión por la ejecución de la operación. Con este instrumento, el bróker pagará al fondo en los casos en los que las acciones o cualquier otro instrumento usado como subyacente bajen de precio en el periodo, de igual modo que el fondo pagará al bróker las subidas de precios del subyacente más los dividendos o cupones que distribuya dicho instrumento.

- Mercado Neutral Renta Variable (Equity market neutral) ${ }^{11}$ : esta estrategia se deriva de la anterior aunque, en este caso, el gestor tratará de evitar que haya cualquier tipo de correlación entre la cartera gestionada y el mer-

\footnotetext{
${ }^{11}$ Jacobs, B., Levy, K. And Anson, M., Market Neutral Strategies. Wiley, USA, 2004.
} 
cado o, dicho en otras palabras, tratará de que la exposición ajustada por beta ${ }^{12}$ de la cartera sea cero, en el mejor de los casos, o que la cartera no presente sesgos sustanciales hacia las posiciones largas o hacia las cortas. La principal diferencia de una estrategia equity market neutral con respecto a la estrategia de tipo long/short radica en el hecho de que, mientras que un gestor especializado en una estrategia long/short tratará de mantener una cartera en la que el peso de las posiciones largas sea mayor que el de las cortas o viceversa, en el caso de una cartera gestionada de acuerdo a la estrategia de tipo equity market neutral tratará de que las posiciones largas y las cortas estén compensadas completamente en cuanto a exposición a movimientos del mercado se refiere, lo cual es bastante más complicado de llevar a cabo en la práctica de lo que dice la teoría.

En el caso de los fondos UCITS y, para poder implementar esta estrategia, los gestores deberán usar diversos productos derivados, por lo que sólo podrá ser puesta en funcionamiento por fondos UCITS sofisticados, siempre y cuando se adapten a los límites y requerimientos exigidos por la regulación aplicable a la industria.

- Ventas en corto (Dedicated short bias) ${ }^{13}$ : en esta estrategia y, al igual que en las anteriores, los analistas del fondo llevarán a cabo un profundo análisis, ya sea aplicando técnicas de análisis fundamental o de análisis técnico, de un gran número de activos para determinar cuáles están sobrevalorados y cuáles infravalorados. Una vez detectados unos y otros, el gestor especializado en este tipo de estrategia se centrará exclusivamente en aquellos que estén sobrevalorados, los cuales venderá en corto con el objetivo de recomprar las acciones una vez hayan caído de precio. En otras palabras, el gestor mantendrá una exposición neta corta que será mayor o menor en función de las coberturas que desee hacer.

De igual modo que sucede en muchos otros casos, esta estrategia requiere de la toma de posiciones cortas para poder ser implementada, por lo que tan sólo los fondos UCITS que tengan un carácter sofisticado podrán llevarla a cabo, para lo cual deberán adaptarse a las obligaciones y restricciones recogidas en la legislación encargada de regular sus actividades.

- Estrategias por eventos (Event driven $)^{14}$ : estas estrategias tienen como principal objetivo el tratar de aprovechar distintas oportunidades que pue-

\footnotetext{
${ }^{12}$ En términos simples, la beta de un valor es una medida del riesgo derivado de la exposición de dicho valor a movimientos del mercado.

${ }^{13}$ Fabozzi, F. and Asness, C., Short Selling: Strategies, Risks, and Rewards. Wiley, USA, 2004.

${ }^{14}$ Kirchner, T., Merger Arbitrage: How to Profit from Event-Driven Arbitrage. Wiley, USA, 2009.
} 
dan surgir en eventos corporativos y situaciones especiales o de carácter extraordinario tales como fusiones, adquisiciones, ventas de activos relevantes, reestructuraciones, bancarrotas, liquidaciones y, en definitiva, toda aquella situación en la cual la estructura de capital de una determinada compañía sufra modificaciones importantes y en las que el valor de la compañía se vea afectado de una manera u otra. A su vez, las estrategias event driven pueden dividirse, por un lado, en las conocidas como estrategias de arbitraje de riesgo o arbitraje de fusiones (merger/risk arbitrage), a través de las cuales el hedge fund o UCITS tratará de anticiparse al resultado final de un evento corporativo, ya sea un éxito o un fracaso del mismo, y tomará posiciones en base a dicho análisis y, por el otro, en las estrategias de activismo en situaciones especiales ${ }^{15}$, en las que, en lugar de esperar a que una determinada situación siga su curso y acabe teniendo un determinado resultado, algunos gestores optan por actuar y participar activamente en el proceso para así poder provocar que la situación acabe del modo más ventajoso para los intereses del fondo.

A la hora de implementar este tipo de estrategias, los gestores de fondos UCITS deberán considerar los límites y obligaciones recogidos en la legislación existente, de igual modo que tendrán que utilizar productos derivados para ponerlas en funcionamiento. Además y, en aquellos casos en los que los gestores participen activamente en una determinada transacción con el objetivo de influir en su resultado, también tendrán que considerar distintas restricciones aplicables a los derechos de voto que, como máximo, podrán adquirir.

- Arbitraje en renta fija (Fixed income arbitrage) ${ }^{16}$ : a la hora de implementar estas estrategias, los fondos llevan a cabo inversiones en activos de renta fija, la cual se denomina de este modo debido al hecho de que permite obtener unas determinadas rentas a los inversores con carácter periódico, al contrario de lo que ocurre con otros activos en los que no hay garantizado por contrato ningún tipo de renta. Algunos ejemplos de estas estrategias son el arbitraje en curva de tipos, en la que el gestor tratará de aprovechar oportunidades que puedan surgir como consecuencia de movimientos en dicha curva; carry trades, en la que el gestor vende en corto un determinado instrumento de renta fija para, con los fondos obtenidos por la venta, comprar otro instrumento que pague un mayor tipo de interés que el que se ha vendido en corto; estrategias con futuros sobre bonos, las

\footnotetext{
${ }^{15}$ Orold, R., Extreme Value Hedging: How Activist Hedge Fund Managers Are Taking on the World. Wiley, USA, 2007.

${ }^{16}$ Huggins, D. and Schaller, C., Fixed Income Relative Value Analysis. Bloomberg Press, UK, 2013.
} 
cuales tratan de aprovechar oportunidades que puedan surgir como consecuencia de las diferencias existentes entre el precio de un futuro sobre un determinado bono y el precio al contado de dicho bono; así como distintas estrategias llevadas a cabo usando productos financieros complejos como $\mathrm{CDOs}^{17}$ (collateralized debt obligations) o $\mathrm{MBS}^{18}$ (mortgage-backed securities) entre diversas otras.

Evidentemente y, al igual que en muchos de los casos comentados con anterioridad, para poder poner en práctica estas estrategias, los gestores de fondos UCITS deberán considerar los distintos límites y restricciones impuestos por la legislación, así como usar diversos instrumentos derivados, por lo que estas estrategias suelen ser implementadas exclusivamente por fondos UCITS sofisticados.

- Arbitraje con bonos convertibles (Convertibles arbitrage) ${ }^{19}$ : los bonos convertibles son uno de los instrumentos que mayor flexibilidad permite a los fondos a la hora de implementar ciertas estrategias, principalmente debido al hecho de que suelen ser vistos como instrumentos en los que los inversores están protegidos de ciertas caídas, siempre que el emisor no tenga problemas que le puedan llevar a un impago o a una quiebra, a lo que se suma el potencial de crecimiento ilimitado que puede tener la acción. Dentro de las distintas estrategias con bonos convertibles que pueden poner en marcha los gestores, destacar que, por lo general, la mayoría de ellas suele tratar de aprovechar oportunidades basadas en comprar opciones de compra (calls) baratas con la expectativa de que el precio de la acción se comporte lo suficientemente bien como para que al tenedor de los bonos le compense llevar a cabo la conversión.

En el caso de los fondos UCITS, todos aquellos gestores que deseen implementar este tipo de estrategias tendrán que considerar las restricciones y límites recogidos en la legislación aplicable, de igual modo que deberán utilizar distintos productos derivados para poder ponerlas en marcha. Este aspecto, hace que tan sólo aquellos fondos UCITS que sean sofisticados puedan llevar a cabo este tipo de estrategias.

${ }^{17} \mathrm{Un} \mathrm{CDO}$ es un tipo de producto estructurado que paga un determinado cupón y devuelve un principal, siempre y cuando los activos que se hayan usado como colateral o garantía a la hora de estructurar el CDO generen los flujos de caja suficientes como para poder pagar dicho cupón y principal.

${ }^{18}$ Un MBS es un tipo de producto estructurado que permite obtener determinados flujos de caja, siempre y cuando los titulares de las hipotecas, ya sean de inmuebles destinados al uso residencial o al comercial, utilizadas como colateral a la hora de estructurar el MBS hagan frente a las cuotas y pagos de las mismas.

${ }^{19}$ Calamos, N., Convertible Arbitrage: Insights and Techniques for Successful Hedging. Wiley, USA, 2003. 
- Macro Global (Global macro) ${ }^{20}$ : la estrategia global macro se caracteriza por ser la estrategia que mayor flexibilidad permite a los gestores a la hora de invertir, ya que utiliza cualquier tipo de activo, ya sea renta variable, renta fija, materias primas, divisas, índices de cualquier tipo e incluso productos derivados. Además, el universo de inversión en términos geográficos también es total, ya que los hedge funds y UCITS especializados en esta estrategia suelen llevar a cabo inversiones tanto en economías desarrolladas, como en emergentes. A la hora de invertir, los gestores global macro llevan a cabo un profundo análisis de la economía o economías en las que pretenden llevar a cabo sus apuestas, con el objetivo de detectar ineficiencias e inconsistencias que puedan existir en variables tales como los tipos de interés, el tipo de cambio de una determinada divisa, el crecimiento del producto interior bruto del país, la balanza comercial, aspectos relacionados con la población y de carácter demográfico, precios de las principales materias primas o incluso en el déficit público presentado por una economía, entre muchas otras. Una vez detectadas las posibles ineficiencias que puedan existir en alguno de los principales indicadores económicos de un determinado país, el gestor tratará de determinar el impacto que puedan tener sobre dichas variables económicas algunas cuestiones de carácter relevante tales como eventos geopolíticos, la caída en el precio de determinadas materias primas, situación económica global, aspectos fundamentales relativos a las finanzas del país y, en definitiva, cualquier evento externo e incontrolable por parte del gobierno que pueda impactar negativa o positivamente en la economía del país.

Por lo general, esta estrategia suele llevarse a cabo tomando posiciones, ya sean largas o cortas, en determinados activos que, generalmente, suelen ser divisas. Por este motivo, los gestores de fondos UCITS que deseen implementar este tipo de estrategia deberán adaptarla a los requerimientos, límites y obligaciones exigidos por la legislación actual a este tipo de vehículos de inversión. Además y, en determinadas ocasiones, para la implementación de esta estrategia tendrán que utilizarse productos derivados que repliquen el comportamiento de las ventas en corto, por lo que en estos casos sólo podrá ser puesta en funcionamiento por aquellos fondos UCITS que sean sofisticados.

- Estrategias con valores en dificultades (Distressed securities) ${ }^{21}$ : esta estrategia, más que una estrategia en sí misma, hace referencia a la implementación de cualquiera de las estrategias anteriormente analizadas sobre ciertos valores, ya sean de renta fija o de renta variable, pertenecientes a compañías que presen-

${ }^{20}$ Gliner, G., Global macro trading: Profiting in a New World Economy. Wiley, USA, 2014.

${ }^{21}$ Whitman, M. and Diz, F., Distress Investing: Principles and Technique. Wiley, USA, 2009. 
ten una situación problemática que pueda dar origen a diversas oportunidades para todos aquellos inversores que decidan arriesgarse a tomar posiciones con el objetivo de aprovecharlas. En este sentido, el mayor número de oportunidades en compañías con problemas suele surgir en épocas en las que la economía de un determinado país, o incluso la economía a nivel global, presenta situaciones de estancamiento económico, desaceleraciones, caídas de actividad o crisis.

En los últimos años y, gracias al apetito de un gran número de inversores por este tipo de estrategias, se han puesto en marcha diversos fondos UCITS especializados en las mismas. No obstante, hay que destacar el hecho de que, debido a las diversas limitaciones y restricciones impuestas por la legislación aplicable a la industria de fondos UCITS, la puesta en funcionamiento de este tipo de estrategias suele ser bastante complicada, ya que la gran mayoría de este tipo de activos no suele presentar los niveles de liquidez mínimos exigidos por la legislación a los fondos UCITS para poder llevar a cabo determinadas inversiones. Por otro lado, destacar también que, en determinadas ocasiones, para poder implementar este tipo de estrategias, los gestores han de utilizar diversos instrumentos derivados, por lo que todos aquellos fondos UCITS especializados en estrategias con distressed securities suelen ser sofisticados.

- Estrategias en mercados emergentes (Emerging markets strategies ${ }^{22}$ : del mismo modo que en el caso de la estrategia anteriormente analizada, las estrategias en mercados emergentes no pueden considerarse como una estrategia en sí misma, ya que hacen referencia a la puesta en marcha de las distintas estrategias analizadas hasta el momento en activos de mercados emergentes, ya sean renta variable, renta fija, divisas, productos derivados o materias primas. El proceso de inversión a la hora de llevar a cabo estrategias en mercados emergentes es exactamente el mismo que el utilizado en la implementación de cualquiera de las estrategias anteriores, con la diferencia de que, en este caso, se deberá poner especial énfasis en la evaluación de los posibles escenarios que puedan tener lugar en el corto, medio y largo plazo en el país. Además y, de igual modo que sucede con las estrategias con valores en dificultades, a la hora de cubrir los posibles riesgos, los hedge funds y UCITS suelen limitar el volumen de fondos invertidos en países emergentes.

En el caso de los fondos UCITS y, de igual modo que sucede con las estrategias con distressed securities, la poca liquidez que, por lo general, suelen presentar los instrumentos existentes en mercados emergentes, hace bastante

\footnotetext{
${ }^{22}$ Gaeta, G., Opportunities in Emerging Markets: Investing in the Economies of Tomorrow. Wiley, USA, 2013.
} 
difícil la puesta en práctica de este tipo de estrategias por parte de este tipo de vehículos de inversión debido a las restricciones, límites y distintas obligaciones recogidas en la legislación actual que han de considerar a la hora de llevar a cabo sus inversiones. Junto a los aspectos anteriormente mencionados, ha de decirse que, en determinadas ocasiones, los fondos UCITS que llevan a cabo estrategias en mercados emergentes utilizan diversos productos derivados, por lo que este tipo de estrategias suele ser más habitual en aquellos fondos UCITS que tengan un carácter sofisticado.

- Futuros gestionados (managed futures ${ }^{23}$ ): el primer aspecto que hay que conocer de este tipo de estrategia es el hecho de que, por lo general, los hedge funds y UCITS que la llevan a cabo operan sobre futuros, contratos a plazo $\mathrm{u}$ opciones sobre cualquier tipo de activo, ya sea renta variable, renta fija, divisas, tipos de interés o materias primas. En el caso de que el fondo opere con materias primas, lo cual es bastante habitual, deberá estar registrado a su vez como un CTA (Commodity Trading Advisor), entendido como todo aquel individuo o firma encargada de prestar servicios de asesoramiento en transacciones con futuros, contratos a plazo u opciones sobre materias primas, o bien como un CPO (Commodity Pool Operator), el cual hace referencia a todo aquel individuo o firma que recibe fondos con el objetivo de ser usados para tomar posiciones en futuros, contratos a plazo u opciones sobre materias primas de todo tipo. Operativamente hablando, esta estrategia implica por parte del fondo, en primer lugar, el desarrollo de sistemas de trading automáticos encargados de analizar las posibles oportunidades que puedan aparecer en los mercados de futuros globales sobre cualquier tipo de activo, aunque en ciertas ocasiones el universo de inversión puede estar restringido a determinadas áreas. Estos sistemas, serán definidos de tal modo que llevarán a cabo decisiones de inversión siempre que se cumplan determinados parámetros introducidos por el desarrollador del sistema, por lo que puede decirse que la importancia del análisis fundamental a la hora de tomar decisiones suele dejarse en un segundo plano para poner especial énfasis en el análisis técnico. No obstante, también hay que decir que, en determinadas ocasiones, los gestores disponen de cierta flexibilidad a la hora de decidir las entradas y salidas en algunas posiciones. En este sentido y, al igual que en otras estrategias, el principal objetivo del sistema será tratar de maximizar los retornos obtenidos, asumiendo los menores riesgos posibles y minimizando los costes de transacción.

De igual modo que en los casos anteriores, para poder aplicar este tipo de estrategia, los fondos UCITS deberán adaptar dichos algoritmos y sistemas de trading a las limitaciones y restricciones incluidas en la legislación aplicable.

\footnotetext{
${ }^{23}$ Clenow, A., Following the Trend: Diversified Managed Futures Trading. Wiley, USA, 2013.
} 
- Fondos de hedge funds y fondos de UCITS 24 : en determinadas ocasiones, algunos fondos de cobertura y fondos UCITS están especializados no en la puesta en marcha de alguna o varias de las distintas estrategias analizadas con anterioridad, sino en la selección de aquellos fondos que sean más exitosos a la hora de desarrollar cada una de dichas estrategias. En otras palabras, estos fondos de hedge funds o de fondos UCITS invierten el dinero de sus inversores en otros fondos de cobertura o UCITS que son los encargados de generar los retornos por medio de alguna de las muchas estrategias que pueden poner en funcionamiento. El principal problema al que se enfrentan estos fondos de fondos no es otro que el tratar de seleccionar a los mejores fondos de cobertura o UCITS de entre los muchos que existen en el mundo, para lo cual llevan a cabo un laborioso, costoso y profundo proceso de due diligence a través del cual tratan de conocer en detalle todas aquellas características del fondo que sea objeto del análisis para, con ello, decidir si invertir o no en dicho fondo.

Por su parte $y$, al igual que ocurre con las estrategias analizadas hasta el momento, a la hora de llevar a cabo inversiones en otros vehículos de inversión, los gestores de los fondos de fondos UCITS tendrán que considerar los distintos límites, restricciones y obligaciones contenidas en la regulación actual. Por otro lado, hay que señalar también el hecho de que la legislación aplicable a las inversiones que pueden llevar a cabo los fondos de fondos UCITS recoge diversas obligaciones específicas para este tipo de vehículos de inversión, dentro de las cuales destacan aspectos tales como la posibilidad que tienen de invertir hasta el 20\% de sus activos bajo gestión en un único fondo UCITS, lo que les permite concentrar parte de sus inversiones, así como el llevar a cabo inversiones de hasta un 10\% de sus activos gestionados en otros fondos no regulados, como por ejemplo hedge funds, entre otros.

- Otras estrategias: además de las estrategias analizadas hasta este momento, existen algunas otras, dentro de las cuales destacan el arbitraje en compañías holding, ya que en determinadas ocasiones pueden aparecer oportunidades en aquellas compañías holding cuyas acciones se intercambien a un NAV (Net Asset Value) $)^{25}$ que sea inferior o superior a la suma de valores de las distintas compañías pertenecientes a dicho holding; el arbitraje con índices, en el que el fondo tratará de aprovechar oportunidades de arbitraje derivadas de la existencia de diferencias entre el valor de un determinado

${ }^{24}$ Nicholas, J., Hedge funds of funds: An investor's guide. Wiley, USA, 2004.

${ }^{25}$ El valor neto de activos o NAV hace referencia al valor de los activos del fondo menos el de sus pasivos. Generalmente, este valor se divide entre el número de participaciones del fondo para llegar al precio o valor de mercado de cada participación. 
futuro sobre un índice y el de los distintos componentes que lo componen; el arbitraje con ETFs (Exchange Traded Funds) ${ }^{26}$ ya que, al igual modo que en los casos anteriores, pueden aparecer oportunidades de arbitraje siempre y cuando existan diferencias entre el NAV del ETF y la suma de los valores de los títulos que componen la cartera del fondo; el arbitraje con ADRs/ GDRs (American/Global Depositary Receipts) ${ }^{27}$, a través de las cuales el fondo tratará de obtener un beneficio en casos en los que un determinado ADR o GDR cotice a un precio distinto al precio de las acciones extranjeras de las cuales es representativo; así como el conocido como trading de volatilidad, a través del cual algunos fondos tratan de aprovechar oportunidades que puedan surgir en determinados productos derivados tales como opciones o swaps, entre otros ${ }^{28}$.

Por lo general, muchas de estas estrategias requieren del uso de determinados productos derivados para poder ser puestas en práctica, por lo que suelen estar restringidas a los fondos UCITS sofisticados. En este sentido, hay que destacar el hecho de que, a la hora de poner en funcionamiento todas aquellas estrategias alternativas que hayan decidido los gestores de un determinado fondo UCITS, el único requisito que deberán cumplir todas ellas es el de estar adaptadas de una manera correcta a los distintos límites, restricciones y obligaciones recogidas por la legislación encargada de regular a este tipo de vehículos de inversión.

Por último, destacar también el hecho de que existen determinados hedge funds y UCITS de carácter multiestratégico especializados en la puesta en práctica de una combinación de varias de las estrategias analizadas con anterioridad aunque, no obstante, hay que decir que estos fondos suelen ser aquellos que presentan un volumen de activos bajo gestión lo suficientemente elevado como para mantener a equipos especializados en varias estrategias. Además, lo más habitual es que un determinado hedge fund o UCITS que lleve a cabo varias estrategias a su vez disponga de varios fondos, cada uno de ellos destinado a implementar una estrategia en concreto, aunque puede darse el caso de que exista un vehículo gestionado por un equipo multidisciplinar de gestores y analistas.

${ }^{26}$ Un ETF hace referencia a un fondo de inversión abierto, es decir, que acepta dinero de nuevos inversores, que cotiza en bolsa.

${ }^{27}$ Los ADRs son títulos representativos de acciones de compañías extranjeras custodiados en un banco depositario, que cotizan en dólares americanos en las distintas bolsas de valores de Estados Unidos. Por otro lado, si dichos títulos representativos son emitidos en varios países, son denominados GDRs.

${ }^{28}$ En el caso de las opciones, los hedge funds suelen apostar a que la volatilidad realizada será inferior o superior a la volatilidad implícita pagada por la opción, de modo que si creen que la volatilidad realizada se situará por encima de la implícita comprarán opciones, mientras que si creen que la volatilidad realizada será inferior a la implícita, las venderán. 


\section{VENTAJAS Y DESVENTAJAS DE LOS FONDOS UCITS CON RESPECTO A LOS HEDGE FUNDS}

\section{Tabla 2. Ventajas y desventajas de los fondos UCITS con respecto a otras alternativas de inversión}

\begin{tabular}{|c|c|}
\hline Ventajas & $\begin{array}{c}\text { Gestión profesional, diversificación, gestión de riesgos, pasaporte eu- } \\
\text { ropeo, prestigio, altamente regulados, menores costes para inversores, } \\
\text { elevada base inversora, transparencia, diversidad de estrategias, alta } \\
\text { liquidez, ventajas fiscales y elevada eficiencia. }\end{array}$ \\
\hline Desventajas & $\begin{array}{c}\text { Flexibilidad limitada, mayor correlación con el mercado, altos costes } \\
\text { de constitución iniciales, elevados costes de algunos UCITS con res- } \\
\text { pecto a instrumentos similares, poca personalización, no distribuidos } \\
\text { en todos los países, menor alineamiento de intereses entre gestores e } \\
\text { inversores y diferencias competitivas entre UCITS. }\end{array}$ \\
\hline
\end{tabular}

Fuente: elaboración propia.

La tabla anterior muestra las principales ventajas y desventajas que presentan los fondos UCITS con respecto a otros vehículos de inversión, las cuales se derivan en gran medida de las restricciones y obligaciones contenidas en la legislación encargada de regular a la industria. Esta robusta legislación ofrece a los inversores de fondos UCITS una protección muy superior a la que tienen todos aquellos individuos que decidan llevar a cabo inversiones en fondos de cobertura aunque, por otra parte, también limita su flexibilidad e impide que puedan gozar de algunas ventajas derivadas de la mucho más laxa regulación a la cual están sujetos los hedge funds.

\section{Ventajas}

- Gestión profesional: el primero de los aspectos positivos que presentan los fondos UCITS es el hecho de que la regulación aplicable a los mismos exige que éstos sean gestionados por una serie de individuos que han de presentar un nivel mínimo de experiencia, conocimientos y reputación dentro de la industria de gestión de activos que les permita llevar a cabo la gestión de los fondos de la mejor manera posible. En este sentido, se exige que las carteras de los fondos UCITS sean gestionadas de una manera eficiente, aplicando para ello una serie de mecanismos y de técnicas de gestión de activos avanzadas destinadas a la construcción y gestión de carteras de acuerdo a los objetivos y reglas del fondo para, con ello, proteger y garantizar los intereses de los inversores. 
- Diversificación: otro aspecto importante que presentan los fondos UCITS es el hecho de que las inversiones realizadas por sus gestores han de presentar un nivel mínimo de diversificación, con el objetivo de evitar que errores a la hora de tomar determinadas decisiones de inversión puedan impactar muy negativamente en el rendimiento del fondo, lo que evita que, en la gran mayoría de los casos, los inversores tengan que hacer frente a cuantiosas pérdidas. En este sentido, la diversificación es uno de los principales aspectos recogidos en las distintas Directivas aplicables a los fondos UCITS, en las cuales se recogen determinados límites y restricciones de obligado cumplimiento en los que se determinan ciertas restricciones a la hora de invertir en determinadas clases de activos, así como a la hora de concentrar inversiones en activos que puedan estar altamente correlacionados entre sí, con el objetivo de evitar que determinados problemas sufridos por un emisor, una industria o un país en concreto puedan poner en riesgo la estabilidad futura del fondo.

- Gestión de riesgos: derivado de los dos aspectos anteriormente mencionados, los fondos UCITS han de ser gestionados aplicando metodologías, políticas y procedimientos de gestión de riesgos destinados a minimizar los riesgos asumidos a la hora de llevar a cabo determinadas inversiones, para lo cual se suelen aplicar distintas técnicas, generalmente cuantitativas, en las que se trata de evaluar los posibles riesgos, así como las posibles pérdidas que sufriría el fondo en el caso de que tuvieran lugar determinados eventos o situaciones en un futuro.

- Pasaporte europeo: el hecho de que un determinado fondo UCITS que haya sido aprobado en uno de los países miembro pueda ser vendido en la totalidad de países de la Unión Europea, facilita en gran medida el desarrollo de este tipo de vehículos de inversión, gracias a que los inversores pueden tener acceso a diversos fondos que implementen distintas estrategias destinadas a alcanzar determinados objetivos de rentabilidad y dirigidas a inversores con distintos perfiles de riesgo, sin necesidad de estar basados en el mismo país de origen de dichos fondos, y todo ello con la protección que otorga la robusta y eficiente legislación aplicable a este tipo de vehículos de inversión. Este pasaporte europeo, a su vez, también es extremadamente positivo para los intereses de todos aquellos que decidan establecer un fondo UCITS, ya que al no tener que registrarse en todos y cada uno de los países en los que se pretenda distribuir el fondo, se aumenta en gran medida la eficiencia y se reducen los costes. Todo ello, permite a la totalidad de fondos UCITS el disponer de una ventaja competitiva muy importante con respecto a otros vehículos de inversión que no sean UCITS. 
- Prestigio: gracias a las distintas campañas puestas en funcionamiento desde la Unión Europea, la industria de fondos UCITS ha venido experimentando un gran crecimiento en su nivel de prestigio dentro del mundo de la gestión de activos. Actualmente, la marca UCITS es percibida por un gran número de inversores, ya no sólo de la Unión Europea, sino también de otras partes del mundo, como un signo de calidad que indica que los intereses de los inversores estarán garantizados en todo momento gracias a la aplicación de diversas técnicas destinadas a limitar los riesgos asumidos por este tipo de vehículos inversión, todo ello sin sacrificar rentabilidades atractivas o estrategias novedosas destinadas a inversores de diversos perfiles de riesgo. Además, también ha de destacarse el hecho de que determinados países externos a la Unión Europea permiten la distribución de diversos fondos UCITS debido al prestigio del que gozan, así como por la alta protección de los intereses de los inversores que garantiza la legislación aplicable a este tipo de vehículos de inversión.

- Altamente regulados: los fondos UCITS han experimentado un gran crecimiento en los últimos años gracias, en parte, a la robusta y eficiente legislación aplicable a todos ellos desarrollada por los distintos países de la Unión Europea en las últimas décadas. En este sentido, los inversores se ven atraídos en gran medida por este tipo de vehículos inversión gracias a la protección que les ofrece la legislación existente, ya que toda ella está destinada a proteger y garantizar los intereses de los inversores, pero permitiendo a su vez que los fondos UCITS dispongan de suficientes herramientas y mecanismos que les permitan presentar un atractivo importante para todos aquellos individuos que estén interesados en obtener rentabilidades interesantes sin poner en demasiado riesgo sus intereses. Junto a este aspecto, la fuerte supervisión por parte de las diversas autoridades de los países de la Unión Europea a la que están sujetos los fondos UCITS, también es un atractivo muy importante a tener en cuenta por todos aquellos inversores que estén dispuestos a invertir en este tipo de productos. Por otro lado, la legislación existente también exige a este tipo de fondos de inversión la puesta en marcha de distintos procedimientos contables y administrativos, mecanismos de control interno y de evaluación de riesgos, así como de protección de datos, que sean lo suficientemente robustos y correctos como para garantizar el desarrollo de la actividad normal del fondo y su estabilidad futura. Junto a ello, también se suele exigir a este tipo de fondos la aceptación de diversos códigos de conducta que les obliguen a llevar a cabo sus diversas actividades de una manera ética, profesional, integra y honesta, con el principal objetivo de evitar posibles fraudes y engaños a los inversores.

- Menores costes para inversores: los fondos UCITS suelen presentar una estructura de costes similar a la de los hedge funds, ya que suele estar compuesta 
por una comisión de gestión aplicable a los activos bajo gestión del fondo, así como por una comisión por rendimiento que el fondo cobrará en aquellos casos en los que haya sido capaz de obtener rendimientos positivos o de batir a un determinado índice fijado en las reglas del fondo. Sin embargo, ha de destacarse el hecho de que, por lo general, tanto la comisión de gestión, como la comisión por rendimiento, cargada por los fondos UCITS a sus inversores, suelen ser inferiores a las que presentan los hedge funds, por lo que este tipo de vehículos de inversión también suele ser atractivo para una gran mayoría de inversores por sus relativamente contenidos costes en comparación con otras alternativas.

- Elevada base inversora: las características que presentan los fondos UCITS los hacen muy atractivos ya no sólo para los inversores minoristas, sino también para muchos inversores institucionales que optan por invertir en este tipo de fondos gracias a la alta regulación que presentan, aspecto que se suma a la cada vez mayor flexibilidad que están obteniendo en los últimos años. Además, el hecho de que presenten un carácter abierto, así como unas menores exigencias a la hora de llevar a cabo inversiones en ellos, también ayuda en gran medida a que el número de inversores que optan por invertir en fondos UCITS sea muy elevado. Este aspecto, es muy positivo para los intereses, ya no sólo de los inversores, sino también de los propios fondos UCITS, ya que el gran número de inversores al cual están dirigidos les suele permitir obtener unos determinados niveles de activos bajo gestión lo suficientemente elevados como para acceder a diversas economías de escala que les permitan aumentar la eficiencia a la hora de llevar a cabo las operaciones cotidianas y, con ello, prestar un mejor servicio a todos sus inversores con unos menores costes.

- Transparencia: otro de los aspectos importantes de los fondos UCITS es el hecho de que presentan unos niveles de transparencia muy elevados en comparación con otros vehículos de inversión colectiva, como por ejemplo los hedge funds, que permiten que todos aquellos individuos que decidan invertir en un fondo UCITS tengan derecho a acceder a una gran cantidad de información relevante sobre el fondo para estar informados en todo momento, ya no sólo del rendimiento obtenido por el mismo, sino también de diversos aspectos de interés. En este sentido, el alto nivel de transparencia de los fondos UCITS se explica, de nuevo, por las diversas obligaciones que exige la legislación aplicable a este tipo de vehículos inversión, en las cuales se hace referencia a aspectos tales como los distintos documentos que han de distribuirse entre los inversores, así como la información que este tipo de fondos han de proporcionar a las autoridades competentes de los países en los que operan con el objetivo de favorecer y permitir una eficiente supervisión de todos ellos. 
- Diversidad de estrategias: independientemente de que la flexibilidad de los fondos UCITS siga siendo inferior a la que se puede encontrar en otros vehículos de inversión colectiva como los hedge funds, es innegable el hecho de que, en los últimos años, se han introducido importantes avances en la legislación que han permitido aumentar la flexibilidad de los fondos UCITS en gran medida. En este sentido, aquellos fondos UCITS que son considerados como sofisticados, tienen la posibilidad de poner en práctica diversas estrategias muy parecidas a las desarrolladas por los hedge funds, todo ello bajo el amparo de una legislación lo suficientemente potente como para garantizar los intereses de la totalidad de sus inversores. Además, en los últimos años también se ha aumentado el número de activos en los cuales los fondos UCITS pueden llevar a cabo inversiones, lo que ha permitido también a este tipo de fondos el desarrollo de estrategias destinadas a aprovechar oportunidades en nuevos activos y mercados en los que años antes no podían invertir.

- Alta liquidez: tal y como se visto, la legislación aplicable encargada de regular la industria de fondos UCITS presenta una serie de restricciones y limitaciones de obligado cumplimiento en las cuales, entre otros aspectos, se recoge el hecho de que las inversiones deberán ser llevadas a cabo en productos que presenten una liquidez elevada, del mismo modo que los fondos deberán permitir a sus inversores suscribir o amortizar unidades de los mismos de una manera sencilla y rápida. Por lo general, los UCITS suelen tener una liquidez diaria o semanal, al contrario que otros vehículos como los hedge funds, por lo que los inversores pueden invertir y recuperar los fondos invertidos sin demasiados problemas, lo que aumenta en gran medida su atractivo.

- Ventajas fiscales: la diversidad de estructuras legales de las que disponen los fondos UCITS a la hora de ser estructurados, les permite aumentar en gran medida su eficiencia fiscal y, con ello, que sus inversores puedan acceder a determinadas ventajas de carácter fiscal que aumentan en gran medida el atractivo de este tipo de fondos.

- Elevada eficiencia: los distintos aspectos aplicables a la industria de fondos UCITS recogidos en la legislación existente, permiten a este tipo de vehículos de inversión el disponer de una elevada eficiencia a la hora de llevar a cabo sus operaciones habituales que, a su vez, les permite obtener ventajas competitivas muy importantes con respecto a otros vehículos de inversión existentes dentro de la industria de gestión de activos. En este sentido, algunas de las estructuras que pueden escoger los fondos UCITS a la hora de establecerse, así como la posibilidad de la que disponen en la actualidad los distintos fondos o compartimentos para fusionarse, permiten a este tipo de 
vehículos de inversión aumentar su eficiencia operativa gracias a la obtención de economías de escala, mejorar los diversos servicios y productos ofrecidos a sus inversores, aumentar la liquidez de sus unidades, incrementar la velocidad a la hora de distribuir sus productos entre inversores de distintos países de la Unión Europea y, en definitiva, adaptarse en mayor medida a las preferencias y deseos de los inversores.

\section{Desventajas}

- Flexibilidad limitada: independientemente de que, en los últimos años, se hayan introducido diversos cambios en la legislación aplicable a la industria de fondos UCITS destinados a aumentar la flexibilidad de este tipo de vehículos de inversión, la flexibilidad de la que disponen sigue siendo inferior a la de los hedge funds. En este sentido, las distintas limitaciones y restricciones a las cuales están sujetos los UCITS a la hora de llevar a cabo sus inversiones, son una limitación importante para obtener retornos superiores e incluso para implementar determinadas estrategias complejas. Este aspecto, puede provocar que ciertos inversores que presenten un perfil de riesgo elevado o que deseen invertir en estrategias alternativas novedosas opten por invertir en hedge funds en lugar de en fondos UCITS, debido al menor valor añadido que, en ocasiones, presentan estos últimos. Por otro lado, los fondos UCITS, al contrario que los hedge funds, y con el objetivo de proporcionar una mayor liquidez a sus inversores, tienen que mantener una determinada cantidad de efectivo que les resta eficiencia, ya que dicho efectivo ha de permanecer inmovilizado por si los inversores desean suscribir o amortizar participaciones del fondo, en lugar de ser utilizado para llevar a cabo inversiones.

- Mayor correlación con el mercado: debido a la menor flexibilidad que presentan los UCITS con respecto a los hedge funds, la correlación de este tipo de vehículos de inversión con el mercado suele ser mayor de la que presentan los hedge funds, los cuales tratan de obtener rendimientos absolutos independientemente de la situación del mercado. Además y, debido a que han de poner especial énfasis en la preservación del capital de sus inversores, existe un número elevado de fondos UCITS que son gestionados de forma pasiva o, lo que es lo mismo, que tratan de replicar el comportamiento de determinados índices, por lo que la composición de las carteras de dichos fondos será prácticamente idéntica a la de dichos índices y, consecuentemente, la correlación entre los fondos y los índices replicados será muy elevada. Este aspecto, ha de ser tenido muy en cuenta por todos aquellos inversores que decidan llevar a cabo inversiones en fondos UCITS ya que, en aquellas situaciones en las que el mercado se encuentre en un momento 
bajista y, debido a la menor flexibilidad de este tipo de fondos, es bastante probable que un gran número de ellos se vea afectado negativamente $y$, consecuentemente, que sus inversores tengan que hacer frente a pérdidas.

- Altos costes de constitución iniciales: a la hora de constituir un UCITS y, como consecuencia de las distintas obligaciones que exige la regulación aplicable a los mismos, todos aquellos individuos que decidan poner en marcha uno de estos fondos tendrán que hacer frente a unos costes elevados que, por lo general, suelen ser superiores a los de otros vehículos de inversión. A este aspecto, también se añade el hecho de que, para todos aquellos fondos UCITS que no dispongan de un determinado volumen de activos bajo gestión, los costes de mantenimiento de la estructura operativa suelen ser bastante elevados, lo que hace de este tipo de vehículos de inversión unas alternativas viables y sostenibles en el futuro a partir de un determinado nivel de activos gestionados.

\section{- Elevados costes de algunos UCITS con respecto a instrumentos similares:} en la actualidad, existe un gran número de fondos UCITS que son gestionados con el principal objetivo de replicar los rendimientos obtenidos por un determinado índice o cesta de valores que, al igual que los demás fondos UCITS, presenta una estructura de costes compleja en la que se suele cargar a los inversores una comisión de gestión y una comisión por rendimiento en aquellos casos en los que el fondo sea capaz de superar al índice, lo cual no siempre ocurre. En este sentido, la comisión de gestión que este tipo de fondos UCITS suele cargar a los inversores por el simple hecho de replicar un determinado índice o cesta de valores, puede ser vista como excesiva si se compara con el coste que tienen otros productos similares, como por ejemplo determinados ETFs, que también son capaces de replicar un índice o una cesta de valores pero, sin embargo, con un coste para el inversor mucho menor.

- Poca personalización: las carteras de los UCITS suelen ser construidas por medio de la aplicación de diversas técnicas cuantitativas que tienen como objetivo el construir carteras diversificadas que sean capaces de alcanzar los objetivos definidos en las reglas del fondo, así como de proteger los intereses de los inversores. Sin embargo, puede haber casos de determinados inversores institucionales o incluso individuos con un perfil de riesgo elevado que no estén de acuerdo con diversas posiciones tomadas por los gestores del fondo, ya sea porque los retornos esperados no sean lo suficientemente elevados, o incluso porque los riesgos asumidos sean distintos a los deseados. En estos casos, el poco control que tienen los inversores a la hora de decidir las posiciones de la cartera, puede ser visto como una desventaja de los fondos UCITS con respecto a otros productos, como por ejemplo las cuentas gestio- 
nadas, en los que los inversores tienen acceso a una gestión profesional y personalizada de acuerdo a los requisitos y directrices definidas por ellos mismos.

- No distribuidos en todos los países: los fondos UCITS, principalmente debido a su elevado prestigio, pueden ser comprados por inversores ya no sólo basados en países de la Unión Europea, sino también en determinados países que, debido a la elevada regulación aplicable a este tipo de productos destinada a proteger los intereses de los inversores, también permiten su distribución a inversores nacionales. Sin embargo, los fondos UCITS no son distribuidos en determinados países del mundo, por lo que todos aquellos inversores basados en estas regiones deberán optar por invertir en otros vehículos de inversión colectiva o, en aquellos casos en los que se pueda, invertir en UCITS indirectamente o por medio de mecanismos que, por lo general, suelen conllevar unos mayores costes.

- Menor alineamiento de intereses entre gestores e inversores: en contraste con lo que sucede en el caso de los hedge funds, los gestores de la gran mayoría de fondos UCITS existentes no suelen ser los principales propietarios de dichos fondos, de igual modo que no suelen invertir un porcentaje demasiado elevado de su patrimonio personal en los fondos gestionados, lo que hace que el alineamiento de intereses entre dichos gestores y los inversores del fondo sea menor que en el caso de los hedge funds. No obstante, hay que destacar también que, en los últimos años, se han llevado a cabo diversas reformas en la legislación aplicable a la industria de fondos UCITS destinadas a fomentar un mayor alineamiento de intereses entre los gestores de un determinado fondo y sus inversores, para lo cual se exige que la política de retribución existente en las compañías gestoras, compañías de inversión y fondos UCITS, trate de promover la consecución de objetivos de rentabilidad atractivos minimizando los riesgos asumidos.

- Diferencias competitivas entre UCITS: el hecho de que los fondos UCITS puedan estructurarse de diferentes maneras, así como la posibilidad que tienen de establecerse en cualquier país de la Unión Europea, hace que, por lo general, la gran mayoría de estos fondos sean creados y registrados en aquellos países que más facilidades y ventajas permiten a los fondos y a sus inversores. Este aspecto, hace que aquellos fondos UCITS que estén basados en países en los que la legislación sea más ventajosa, presenten importantes ventajas competitivas con respecto a otros fondos establecidos en países en los que las ventajas para el fondo y sus inversores sean menores. En este sentido, un gran número de fondos UCITS ha optado por establecerse en países como Luxemburgo o Irlanda debido a las facilidades existentes en los mismos, así como por las diversas ventajas que ofrecen con respecto a otros países de la Unión Europea. 


\section{CONCLUSIONES}

Es evidente que los cambios introducidos en los últimos años en la legislación aplicable a la industria de fondos UCITS han permitido a este tipo de vehículos de inversión aumentar su flexibilidad en gran medida y acercarlos, aún más si cabe, a los fondos de cobertura. De hecho, en la actualidad, existe un gran número de fondos UCITS que implementa novedosas estrategias alternativas que tienen como principal objetivo la obtención de rentabilidades absolutas, independientemente de la situación por la que atraviese el mercado, y todo ello protegiendo los intereses de sus inversores gracias en parte a las muy diversas limitaciones y obligaciones recogidas en la legislación encargada de regular su industria.

Sin embargo e, independientemente de que la evolución que ha experimentado la industria de fondos UCITS en las últimas fechas ha sido muy notoria en términos de posibilidades a la hora de implementar diversas estrategias de inversión, así como de activos en los que invertir, todavía a día de hoy las restricciones, limitaciones y obligaciones a las que han de hacer frente les resta flexibilidad para poder poner en marcha estrategias idénticas a las implementadas por otros vehículos de inversión que gozan de una mucho más laxa regulación, como por ejemplo los fondos de cobertura. En este sentido, los fondos UCITS que deseen poner en funcionamiento estrategias alternativas que, en muchos de los casos, presenten un nivel de complejidad superior al que se puede encontrar en la industria de gestión de activos tradicional, deberán presentar un carácter sofisticado ya que, de lo contrario, las limitaciones a las que se enfrentarán harán prácticamente imposible la puesta en marcha de ciertas estrategias que, en muchas ocasiones, serán una de las pocas alternativas de las que dispondrán los gestores para poder aprovechar situaciones de mercado específicas e incluso ineficiencias que puedan surgir en los precios de determinados activos. En estos casos, los gestores de fondos UCITS que deseen implementar estrategias similares a las puestas en marcha por los fondos de cobertura, deberán adaptarlas a las limitaciones y exigencias incluidas en la legislación encargada de regular su industria que, en la mayoría de los casos, determina los activos en los que este tipo de vehículos de inversión tienen autorizado llevar a cabo inversiones, el nivel de liquidez mínimo exigido a dichos activos, así como aspectos relativos a niveles mínimos de diversificación que, en todos los casos, tienen como principal objetivo el proteger los intereses de todos aquellos inversores que decidan llevar a cabo inversiones en este tipo de fondos.

Por último, no debe dejar de mencionarse que, aunque la legislación actual encargada de regular la industria de fondos UCITS aún siga presentando aspectos mejorables, es innegable el hecho de que la protección que brinda a los inversores pasa por ser una de las más avanzadas y eficientes de las que se pueden encontrar 
en la industria de gestión de activos a nivel global. Este aspecto, junto con otras importantes cuestiones recogidas en la misma, permite que los fondos UCITS presenten una serie de ventajas muy a tener en cuenta por todos aquellos individuos que se estén planteando invertir en este tipo de vehículos de inversión aunque, no obstante y por otro lado, esta mayor protección de los inversores introducida por la regulación actual también lleva aparejada una serie de aspectos que pueden ser vistos como inconvenientes o desventajas frente a otros vehículos de inversión, como por ejemplo los hedge funds, que gozan de una flexibilidad total a la hora de llevar a cabo sus operaciones e implementar cualquier tipo de estrategia de inversión, gracias en parte a la prácticamente nula legislación encargada de su regulación. En este sentido, dentro de las ventajas de los UCITS destacan aspectos tales como el alto nivel de diversificación, la alta transparencia, la alta liquidez, así como el alto nivel de regulación al que están sujetos. Por otro lado, algunas de las principales desventajas de este tipo de vehículos de inversión son su menor flexibilidad para implementar determinadas estrategias, su por lo general mayor correlación con el mercado, el menor alineamiento de intereses entre gestores e inversores, así como el hecho de que no son distribuidos en todos los países.

\section{BIBLIOGRAFÍA}

CALAMOS, N., Convertible Arbitrage: Insights and Techniques for Successful Hedging. Wiley, USA, 2003.

CLENOW, A., Following the Trend: Diversified Managed Futures Trading. Wiley, USA, 2013.

DIRECTIVA 2001/108/CE DEL PARLAMENTO EUROPEO Y DEL CONSEJO, de 21 de enero de 2002, por la que se modifica la Directiva 85/611/ CEE del Consejo por la que se coordinan las disposiciones legales, reglamentarias y administrativas sobre determinados Organismos de inversión colectiva en valores mobiliarios (OICVM), en lo que se refiere a las inversiones de los OICVM. DOCE num. L 041 de 13/02/2002, pp. 0035 - 0042. Tambien disponible en http:/eur-lex.europa.eu/legal-content/ES/TXT/ HTML/?uri=CELEX:32001L0108\& from $=$ en

DIRECTIVA 85/611/EEC, de diciembre de 1985, por la que se coordinan las disposiciones legales, reglamentarias y administrativas sobre determinados organismos de inversión colectiva en valores mobiliarios (OICVM) (85/611/CEE). DOCE n L 375 de 31/12/1985, pp. 0003 - 0018. También disponible en http://eur-lex.europa.eu/legal-content/ES/TXT/HTML/?uri $=$ CELEX:31985L0611 from $=$ en

FABOZZI, F. and ASNESS, C., Short Selling: Strategies, Risks, and Rewards. Wiley, USA, 2004. 
GAETA, G., Opportunities in Emerging Markets: Investing in the Economies of Tomorrow. Wiley, USA, 2013.

GLINER, G., Global macro trading: Profiting in a New World Economy. Wiley, USA, 2014.

HUGGINS, D. and SCHALlER, C., Fixed Income Relative Value Analysis. Bloomberg Press, UK, 2013.

JACOBS, B., LEVY, K. and ANSON, M., Market Neutral Strategies. Wiley, USA, 2004.

KIRCHNER, T., Merger Arbitrage: How to Profit from Event-Driven Arbitrage. Wiley, USA, 2009.

LEIBOWITZ, M., EMRICH, S. and BOVA, A., Modern Portfolio Management: Active Long/Short 130/30 Equity Strategies. Wiley, USA, 2009.

LHABITANT, F, Handbook of Hedge Funds. Wiley, USA, 2006.

NICHOLAS, J., Hedge funds of funds: An investor's guide. Wiley, USA, 2004.

OROLD, R., Extreme Value Hedging: How Activist Hedge Fund Managers Are Taking on the World. Wiley, USA, 2007.

STEFANINI, F., VISMARA, S., MEOLI, M. and DEROSSI, T., Newcits: Investing in UCITS Compliant Hedge Funds. Wiley, UK, 2010.

STEFANINI, F., Investment Strategies of Hedge Funds. Wiley, UK, 2006.

SZYLAR, C., UCITS Handbook. Wiley, UK, 2012.

WHITMAN, M. and DIZ, F., Distress Investing: Principles and Technique. Wiley, USA, 2009. 